\title{
Economical fabrication of graphite/paper-based humidity sensor
}

\author{
Shuthish Elangkovan, Mastura Shafinaz Zainal Abidin, Shaharin Fadzli Abd Rahman, \\ Mohammad Shafiq Che Soh, Ahmad Bukhairi Md Rashid \\ School of Electrical Engineering, Faculty of Engineering, Universiti Teknologi Malaysia, Malaysia
}

\begin{tabular}{|c|c|}
\hline Article Info & ABSTRACT \\
\hline Article history: & \multirow{9}{*}{$\begin{array}{l}\text { Paper is regarded as a promising alternative for low-cost and biodegradable } \\
\text { substrate. Paper can be a very good humidity detecting substrate due to its } \\
\text { capability to absorb water vapour, thanks to its porous surface. This work } \\
\text { explores the feasibility of developing a paper-based humidity sensor using } \\
\text { simple and low cost fabrication process. Two type of electrode structures, } \\
\text { namely interdigitated and parallel electrode, were formed by using two } \\
\text { different pencil grade. The pencil grades used were } 2 \mathrm{~B} \text { and } 6 \mathrm{~B} \text {. The current- } \\
\text { voltage (I-V) characteristics of the fabricated device were measured under } \\
\text { different relative humidity and its humidity sensing operation was analyzed. } \\
\text { It was observed that the sensor with the } 6 \mathrm{~B} \text { and parallel electrode } \\
\text { configuration was the most responsive to humidity changes while the } 6 \mathrm{~B} \\
\text { interdigitated sensor was the second best. The sensors fabricated with the } 6 \mathrm{~B} \\
\text { electrodes are better at sensing humidity changes compared to the sensors } \\
\text { fabricated using } 2 \mathrm{~B} \text { electrodes }\end{array}$} \\
\hline Received Jan 25, 2020 & \\
\hline Revised Mar 29, 2020 & \\
\hline Accepted Apr 14, 2020 & \\
\hline Keywords: & \\
\hline Filter paper & \\
\hline Graphite & \\
\hline Humidity & \\
\hline Sensor & \\
\hline
\end{tabular}

Copyright $\odot 2020$ Institute of Advanced Engineering and Science. All rights reserved.

\section{Corresponding Author:}

Mastura Shafinaz Zainal Abidin,

School of Electrical Engineering, Faculty of Engineering,

Universiti Teknologi Malaysia, 81310 Johor Bahru, Malaysia.

Email: m-shafinaz@utm.my

\section{INTRODUCTION}

Humidity sensor is a device that is used to sense and detect the concentration of water vapour in various substances or in the air. Humidity sensors have been employed in various industries such as the food industry and the medical industry [1-3]. However, the issue with current humidity sensors [4-6] is that their methods of fabrication are way too complex, costs too much and there arises a whole lot of issues when disposing the sensor. For example, glazed ceramic used in the sensor releases harmful gases during the decomposition.

This is where paper-based sensors [6-18]comes in as an alternative technique of making a humidity sensor that is easy to fabricate, low-cost, portable as well as being easily disposable [11, 18-20]. Moreover, paper has unique properties which allows passive liquid transport and is compatible with biochemical [18]. Nevertheless, fabrication of paper-based humidity sensing device is still largely unexplored [9, 15, 21, 22]. This study focuses on developing a cost-effective humidity sensor that can be used by everyone for a shortterm and easily disposable. In addition to being cost-effective, the developed prototype is also easily applied to monitor significant changes in humidity. The level of humidity can be seen as the changes in current at specific voltage applied. Different types of graphite were used as the electrode and humidity detecting substrate in developing the prototype sensor [17]. The paper chosen in this study was filter paper. The reason for using filter paper is because it is chemically inert compared to other papers. Graphite chosen was varied according to variation of the amount of clay and graphite composition which was represented by the pencil grade $2 \mathrm{~B}$ and $6 \mathrm{~B}$ respectively [23]. The sensing region for both the sensors were approximately the same which is around $1 \mathrm{~cm}^{2}$. 
The significance of this study is that it looks into the possibility of producing a low-cost humidity sensor with views into much easier and economical fabrication methods. The sensor is also meant to be small hence saving space in materials it is to be implemented. It should be noted that the sensor is environmentally friendly as the materials used are bio-degradable and will not cause foreseeable damage to the environment.

\section{RESEARCH METHOD}

The experimental work was designed and performed in order to address these two aims: (i) to evaluate the suitability of the graphite type used to fabricate the prototype sensor, and (ii) to identify the best working sensor design. Two different sensor designs were fabricated as shown in Figure 1. The first design was called interdigitated electrode (IDE) while the second design was denoted as parallel electrode (PE). The process was done by drawing the design traces manually by hand with two different pencil grades that acted as the source of graphite which were $2 \mathrm{~B}$ and $6 \mathrm{~B}$. Generally, 6B pencil has higher amount of graphite compare to 2B [23]. 6B pencil consists of $84 \%$ graphite and $10 \%$ clay, while 2B pencil consists of $74 \%$ graphite and $20 \%$ clay. The variations of sensor device are shown in Table 1.

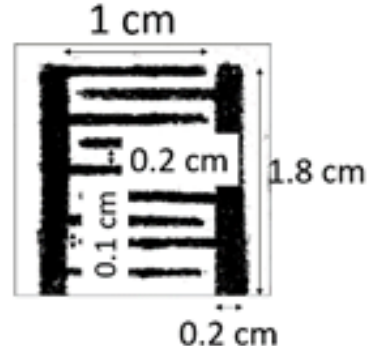

(a)

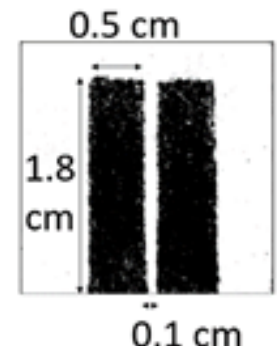

(b)

Figure 1. Device design of a) interdigitated electrode (IDE), and b) parallel electrode (PE)

\begin{tabular}{|c|c|c|}
\hline Sample name & Electrode design & Pencil type \\
\hline IDE-2B & IDE & $2 \mathrm{~B}$ \\
\hline IDE-6B & IDE & $6 \mathrm{~B}$ \\
\hline PE-2B & PE & 2B \\
\hline PE-6B & $\mathrm{PE}$ & $6 \mathrm{~B}$ \\
\hline
\end{tabular}

Figure 2 summarizes the overall flow of the processes involved in this expeperimental study. Initially, the filter paper was cut into a dimension of $2 \mathrm{~cm} \times 2 \mathrm{~cm}$ and then the sensing region was traced on the filter paper according to the designed dimension. Verification of the graphite sensor is done through measurement of current-voltage (I-V) curve. A working fabricated device should exhibit consistent I-V characteristic which showed current increase at higher voltage.

To characterize the humidity sensing operation, the I-V characteristics of each samples were measured at different relative humidity ( $\mathrm{rH}$ ) level. The I-V measurement was done using the Keithley 2000 Multimeter at voltage range of $-10 \mathrm{~V}$ to $10 \mathrm{~V}$. Different $\mathrm{rH}$ levels was obtained by using different saturated salt solution. The measurement setup is shown in Figure 3. The sample was placed inside a container with saturated salt solution. The saturated salt regulates the $\mathrm{rH}$ level inside the container. Different saturated salt solution is known to give different $\mathrm{rH}$ levels. A hygrometer was used to measure the humidity inside the container. Summary pf the salt solution used in this study and their $\mathrm{rH}$ levels measured at room temperature were given in Table 2 [24]. 


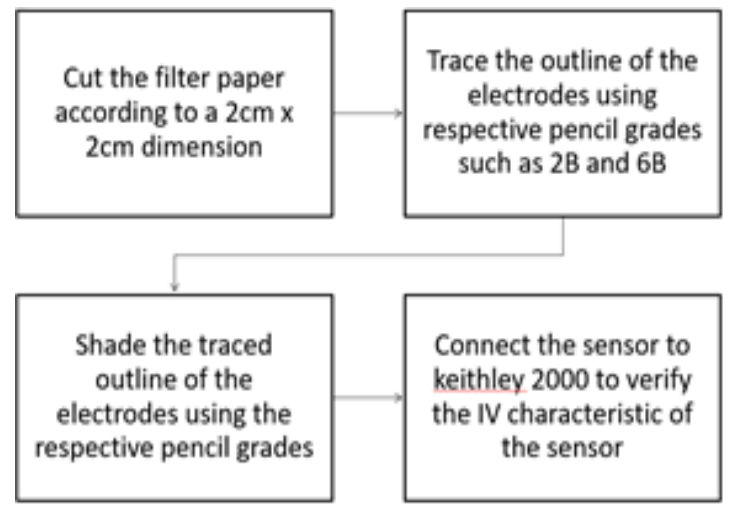

Figure 2.The process flow of the development of the sensor

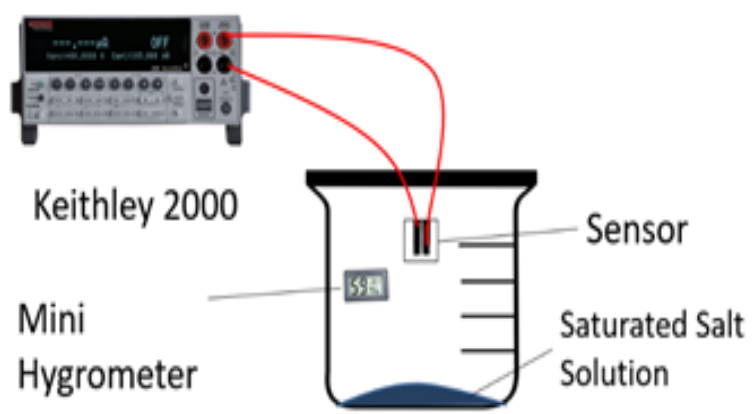

Figure 3. The experimental setup used to obtain I-V characteristics at different humidity levels

Table 2. Salt solution and their humidity levels

\begin{tabular}{lc}
\hline \multicolumn{1}{c}{ Salt Solution } & $\mathrm{rH}(\%)$ \\
\hline Lithium Chloride & 11.31 \\
Magnesium Chloride & 33.07 \\
Magnesium Nitrate & 54.38 \\
Potassium Chloride & 85.11 \\
\hline
\end{tabular}

\section{RESULTS AND ANALYSIS}

Figure 4 shows the measured I-V characteristics of all the device variation. All the sensors did respond to humidity changes. Sensor current increased at higher RH level. Sample made from 6B pencil gave higher current value compared to sample made from $2 \mathrm{~B}$ pencil. It is observed that the higher percentage of graphite leads to higher conductivity.

In order to analyze the sensor response toward $\mathrm{rH}$ changes, graph of current versus $\mathrm{rH}$ was plotted. The current value was taken at $10 \mathrm{~V}$ applied voltage. Figure 5 shows the plot for 4 different sensor types. The sensors fabricated with a $6 \mathrm{~B}$ electrode had the most linear change with humidity as expected while the sensors with $2 \mathrm{~B}$ electrodes had slight fluctuating currents repsonse. This happened due to graphite composition of the $6 \mathrm{~B}$ pencil which is relatively higher hence shows better response in terms of current changes trend with respect to humidity level. Therefore, sensors fabricated with the $6 \mathrm{~B}$ pencil was found to be more suitable for detecting humidity. Altogether, the $6 \mathrm{~B}$ parallel sensor has given the most acceptable result in terms of the current changes according to humidity level. The inaccuracies could be due to the sensors being fabricated by human hand-pressure instead of the controlled auto-mechanized systems. The possibility of the pencil traces being worn out throughout the experiment could also be a causal factor.

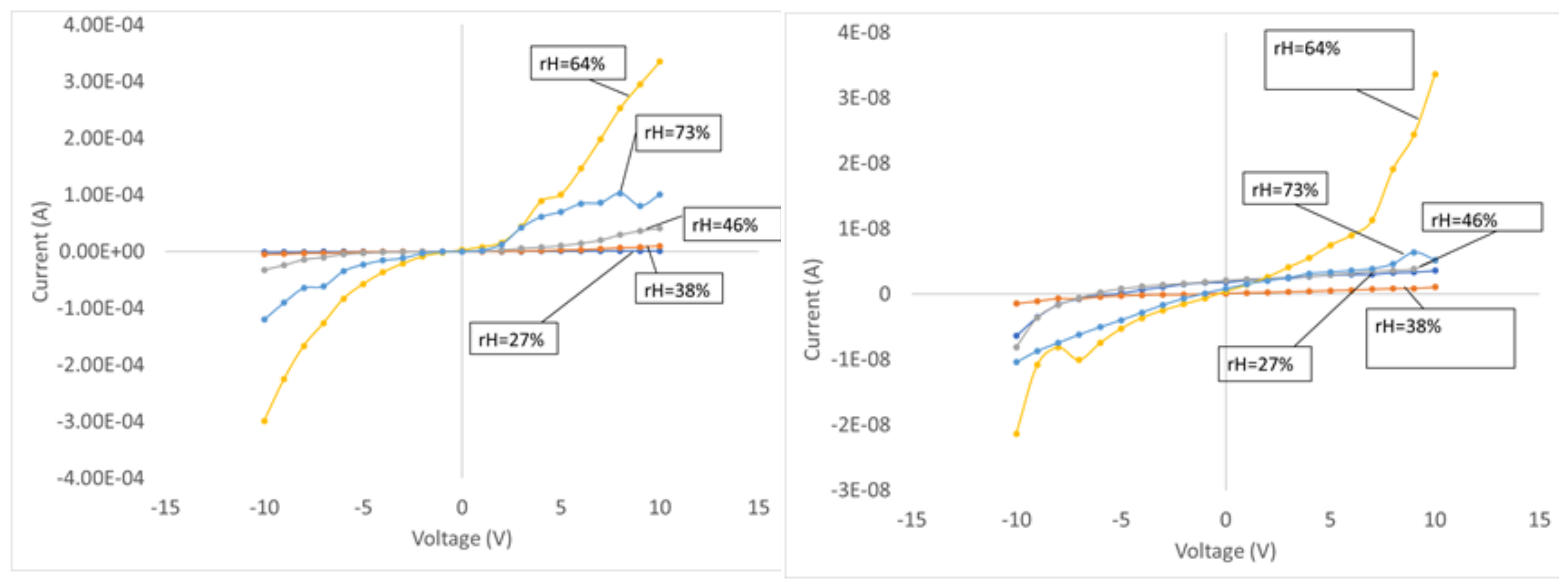

(a) PE-2B

(b) IDE-2B 


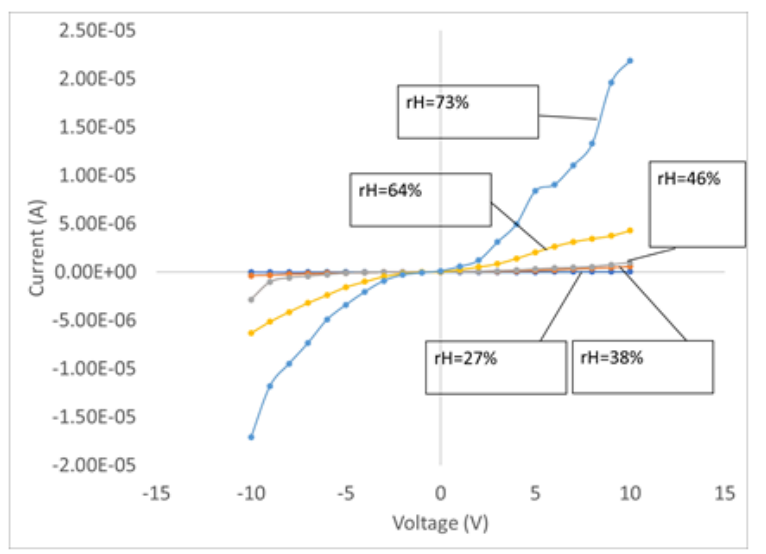

(c) PE-6B parallel

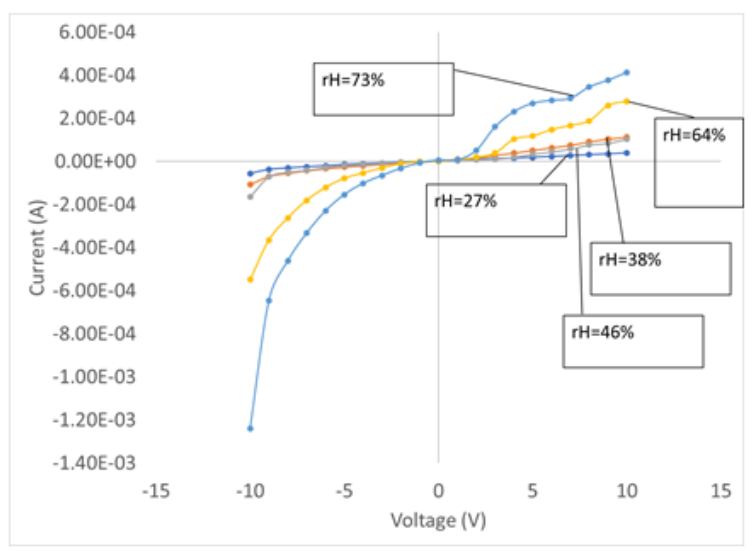

(d) IDE-6B

Figure 4. I-V characteristic of each prototype sensor

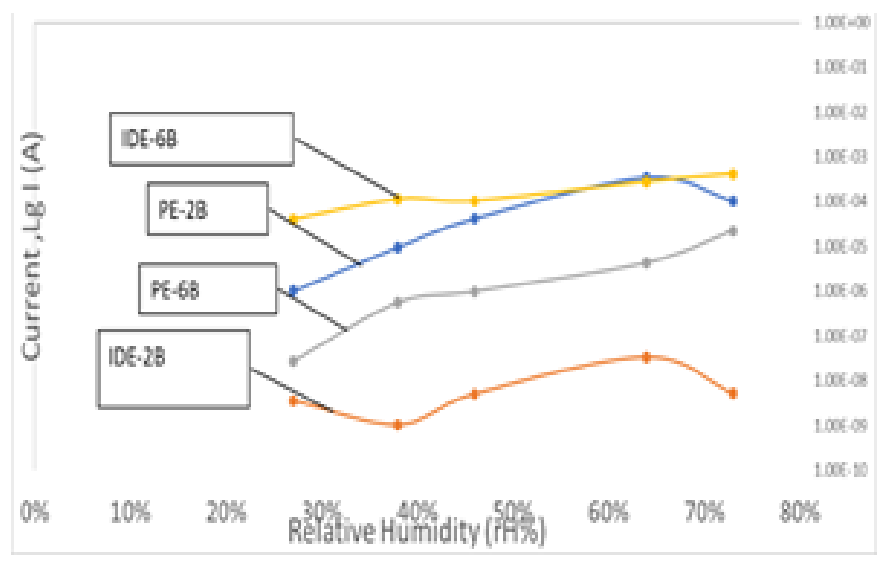

Figure 5. Current changes at $10 \mathrm{~V}$ for different humidity levels of each respective sensor

The experiment indicated that the sensors fabricated using the $6 \mathrm{~B}$ pencil has better response to humidity changes. However, out of the two sensor design, it is seen that the $6 \mathrm{~B}$ parallel sensor gave the most successful result. While the $6 \mathrm{~B}$ interdigitated sensor had a more robust current response, the $6 \mathrm{~B}$ parallel sensor gave the most acceptable I-V characteristic pattern that satisfies the hypotheses which is current increases when humidity levels increases. It was evidenced that relative resistance (RR) can be used to predict the humidity $[12,25]$. The relative resistance $(\mathrm{RR})$ is defined as follow:

$$
R R=\frac{\text { Resistance at corresponding humidity, } R}{\text { Resistance at lowest humidity recorded, } R^{\prime}}
$$

From the obtained I-V characteristics of $6 \mathrm{~B}$ samples, the RR values were extracted and then, the graph of RR against $\mathrm{rH}$ was plotted as shown in Figure 6. As shown in Figure 6, a trendline was obtained for both the sensors. This trendline shows the relationship of the RR and $\mathrm{rH}$. Substituting relative resistance into $\mathrm{y}$ of the equation obtained from the trendline would allow the humidity to be calculated. However, this trendline would not be identical for every sensor that could be fabricated from methods shown in this study. This is because the sensor is fabricated by human hand-pressure and can therefore be defective as the margin for error is huge. However, the measurement technique demonstrated could be used as a suitable method to calculate humidity based on the current changes exhibited by the sensor. 


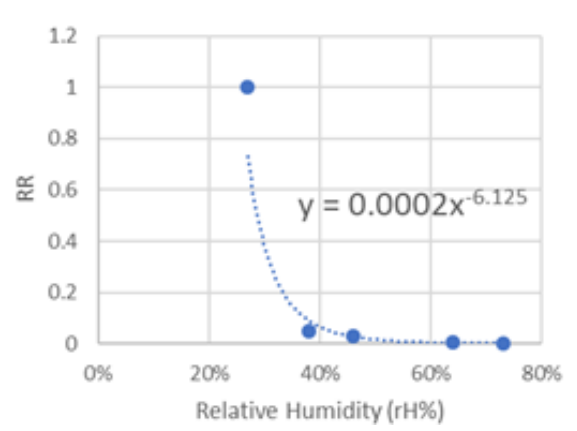

(a)

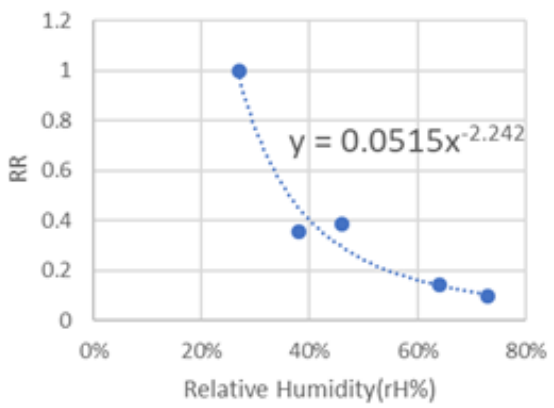

(b)

Figure 6. RR against $\mathrm{rH}$ of $6 \mathrm{~B}$ sample with electrode design of a) $\mathrm{PE}$, and b) IDE

\section{CONCLUSION}

In this study, the fabrication of a simple and low-cost humidity sensing device was demonstrated. It has advantage in terms of being environmental friendly as well as cost-effective. Based on the experiment, the sensor that was fabricated using $6 \mathrm{~B}$ pencil with a parallel electrode configuration gave the best response to humidity. Though the repeatability of the experimental results is a question mark, it is however a good start to note that sensors made as easy as tracing a pencil on paper can be used to measure humidity. Hence, more research needs to be done to develop a sensor that can consistently give results and then be implemented in the industry namely, the food packaging industry where such a sensor can prove to be very crucial. It is expected that the sensor developed in this study can be further optimized to measure humidity levels even more accurately.

\section{ACKNOWLEDGEMENTS}

This work has been supported by Universiti Teknologi Malaysia and Ministry of Higher Education (Grant no: R.J130000.7823.4F926, FRGS/1/2017/TK04/UTM/02/33).

\section{REFERENCES}

[1] Wang, Y., et al., "Application of humidity sensors and an interactive device," Sensors and Actuators B: Chemical, vol. 115, no. 1, pp. 93-101, 2006.

[2] Lee, C.-Y. and G.-B. Lee, "Humidity Sensors: A Review," Sensor Letters, vol. 3, no. 1-4, pp. 1-15, 2005.

[3] Chen, Z. and C. Lu, "Humidity Sensors: A Review of Materials and Mechanisms," Sensor Letters, vol. 3, no. 4, pp. 274-295, 2005.

[4] Farahani, H., R. Wagiran, and M. N. Hamidon, "Humidity Sensors Principle, Mechanism, and Fabrication Technologies: A Comprehensive Review," Sensors, vol. 14, no. 5, pp. 7881-7939, 2014.

[5] Sikarwar, S. and B.C. Yadav, "Opto-electronic humidity sensor: A review," Sensors and Actuators A: Physical, vol. 233, pp. 54-70, 2015.

[6] Reddy, A.S.G., et al., "Fully Printed Flexible Humidity Sensor," Procedia Engineering, vol. 25, pp. 120-123, 2011.

[7] Cheng, C.-M., et al., "Paper-Based ELISA," Angewandte Chemie International Edition, vol. 49, no. 28, pp. 4771-4774, 2010.

[8] Han, J. -W., et al., "Carbon Nanotube Based Humidity Sensor on Cellulose Paper," The Journal of Physical Chemistry C, vol. 116, no. 41, pp. 22094-22097, 2012.

[9] Nery, E. W. and L. T. Kubota, "Sensing approaches on paper-based devices: a review," Analytical and Bioanalytical Chemistry, vol. 405, no. 24, pp. 7573-7595, 2013.

[10] Barmpakos, D., et al., "A disposable flexible humidity sensor directly printed on paper for medical applications," in Journal of Physics Conference Series, vol. 931, 2017.

[11] Gaspar, C., et al., "Paper as Active Layer in Inkjet-Printed Capacitive Humidity Sensors," Sensors, vol. 17, no. 7, p. 1464, 2017.

[12] Niarchos, G., et al., "Paper-based Humidity Sensor Coated with $\mathrm{ZnO}$ Nanoparticles: The Influence of ZnO," Procedia Engineering, vol. 168, pp. 325-328, 2016.

[13] Xue, P. and Y. Kang, "Paper-Based Sensors and Microfluidic Chips, in Encyclopedia of Microfluidics and Nanofluidics," Springer Link, pp. 2647-2655, 2014.

[14] Singh, A. T., et al., "Paper-Based Sensors: Emerging Themes and Applications," Sensors, vol. 18, no. 9, p. $2838,2018$.

[15] Gimenez, A. J., et al., "Paper-Based ZnO Oxygen Sensor,” IEEE Sensors Journal, vol. 15, no. 2, pp. 1246-1251, 2015.

[16] Kurra, N. and G. U. Kulkarni, “Pencil-on-paper: electronic devices,” Lab on a Chip, vol. 15, no. 13, pp. 2866-2873, 2013.

[17] Zhang, J., et al., "Pencil-trace on printed silver interdigitated electrodes for paper-based NO2 gas sensors," Applied Physics Letters, vol. 106, no. 14, p. 143101, 2015. 
[18] Liana, D. D., et al., "Recent Advances in Paper-Based Sensors," Sensors, vol. 12, no. 9, pp. 11505-11526, 2012.

[19] Cunningham, J. C., P. R. DeGregory, and R. M. Crooks, "New Functionalities for Paper-Based Sensors Lead to Simplified User Operation, Lower Limits of Detection, and New Applications," Annu Rev Anal Chem (Palo Alto Calif), vol. 9, no. 1, pp. 183-202, 2016.

[20] Singh, A. T., et al., "Paper-Based Sensors: Emerging Themes and Applications," Sensors, vol. 18, no. 9, p. $2838,2018$.

[21] Li, X., et al., "Fabrication of paper-based microfluidic sensors by printing," Colloids and Surfaces B: Biointerfaces, vol. 76, no. 2, pp. 564-570, 2010.

[22] Courbat, J., et al., "Inkjet printing on paper for the realization of humidity and temperature sensors," 2011 16th International Solid-State Sensors, Actuators and Microsystems Conference, Beijing, pp. 1356-1359, 2011.

[23] Bhowmik, R., "Ferromagnetism in lead graphite-pencils and magnetic composite with CoFe $2 \mathrm{O} 4$ particles," Composites Part B: Engineering, vol. 43, no. 2, pp. 503-309, 2012.

[24] Carotenuto, A. and M. Dell'Isola, "An experimental verification of saturated salt solution-based humidity fixed points," International Journal of Thermophysics, vol. 17, no. 6, pp. 1423-1439, 1996.

[25] Niarchos, G., et al., "Humidity Sensing Properties of Paper Substrates and Their Passivation with ZnO Nanoparticles for Sensor Applications," Sensors (Basel), vol. 17, no. 3, 2017.

\section{BIOGRAPHIES OF AUTHORS}
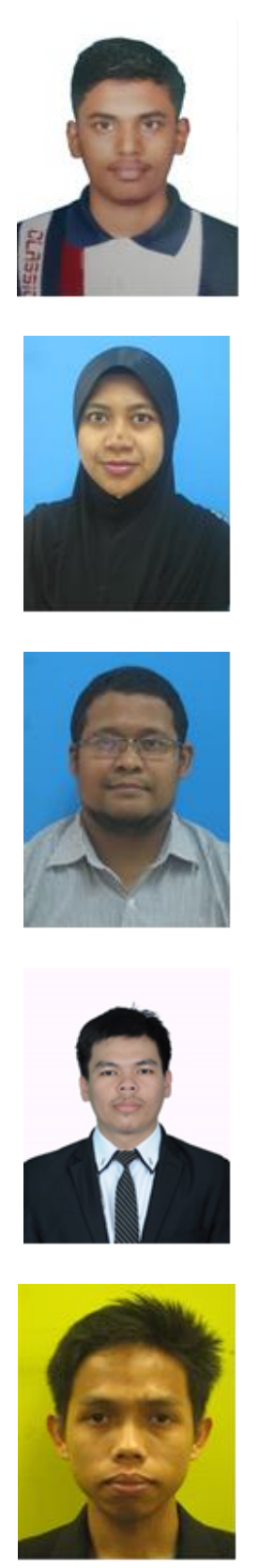

Shuthish Elangkovan has completed his Bachelor of Engineering (Electrical-Electronics) from Universiti Teknologi Malaysia, Malaysia in 2019.

Mastura Shafinaz Zainal Abidin is a Senior Lecturer in School of Electrical Engineering, Faculty of Engineering, Universiti Teknologi Malaysia, Malaysia. She obtained her Bachelor of Engineering (Electrical-Electronics) in 2008, Masters of Electrical Engineering-Electronics and Telecommunications in 2010; and Doctor of Philosophy in Electrical Engineering in 2014 from Universiti Teknologi Malaysia. Her research interest is semiconductor, electronic device, sensor fabrication and characterization.

Shaharin Fadzli Abd Rahman is a Senior Lecturer in School of Electrical Engineering, Faculty of Engineering, Universiti Teknologi Malaysia, Malaysia. He completed his Bachelor of Engineering degree and Master of Engineering from Hokkaido University, Japan in 2007 and 2009, respectively. In 2013, he obtained Doctor of Philosophy in Electrical Engineering from Universiti Teknologi Malaysia, Malaysia. His research interest is semiconductor and graphenebased electronic device and sensor fabrication and characterization.

Mohammad Shafiq Che Soh has completed his Bachelor of Engineering (ElectricalElectronics) from Universiti Teknologi Malaysia, Malaysia in 2019.

Ahmad Bukhairi Md Rashid is currently doing his Master of Philosphy degree in Electrical Engineering at School of Electrical Engineering, Universiti Teknologi Malaysia, Malaysia. He completed his Bachelor of Engineering (Electrical-Electronics) from Universiti Teknologi Malaysia, Malaysia in 2017. 